\title{
AlocaÇÃo de Biomassa e NUTRIEnTES EM Heteranthera reniformis SOB O EFEITO DE N, P E $\mathbf{K}^{1}$
}

\author{
Allocation of Biomass and Nutrients in Heteranthera reniformis under the Effect of $N$, $P$ and $K$
}

DOMINGOS, V.D. ${ }^{2}$, MARTINS, D. ${ }^{3}$, FERNANDES, D.M. ${ }^{3}$; COSTA, N.V. ${ }^{2}$ e PASCHOA, P.L. ${ }^{4}$

\begin{abstract}
RESUMO - Este trabalho objetivou estudar a distribuição de biomassa e nutrientes entre os componentes vegetativos de Heteranthera reniformis sob o efeito de diferentes concentrações de $\mathrm{N}, \mathrm{P}$ e K. As plantas foram cultivadas em vasos plásticos preenchidos com pedra rolada, em soluções nutritivas a $80 \%$ da concentração original de Sarruge, sendo esta a solução-base. O delineamento experimental utilizado foi o inteiramente casualizado, com quatro níveis $(0,25,50$ e $75 \%$ da solução-base) avaliados individualmente em N, P e K, além da testemunha ( $100 \%$ da solução-base), com quatro repetições no período de 35 dias. As maiores áreas foliares ocorreram em soluções com $75 \%$ de P e $50 \%$ de $\mathrm{N}$ e K. A solução com $50 \%$ de $\mathrm{N}$ proporcionou a maior biomassa seca de plantas. A contribuição do caule na alocação de recursos apresentou resultados que variaram entre 55,5 e 74,5\% em relação à matéria seca total referente ao nível 0 e $75 \%$ de N; a contribuição de raízes reduziu com o aumento da concentração de $\mathrm{N}$, bem como de $\mathrm{P}$ e $\mathrm{K}$. As maiores contribuições de raízes ocorreram nas ausências de $\mathrm{N}(26,8 \%)$ e $\mathrm{P}(19,2 \%)$, os quais foram maiores em relação aos seus respectivos níveis mais concentrados. Os teores de N, P e K corresponderam a uma ordem crescente em folha, caule e raízes, em que os maiores teores foram obtidos nos níveis de 50 a $125 \mathrm{mg} \mathrm{L}^{-1}$ de $\mathrm{N}, 5$ a $15 \mathrm{mg} \mathrm{L}^{-1}$ de $\mathrm{P}$ e 100 a $150 \mathrm{mg} \mathrm{L}^{-1}$ de $\mathrm{K}$.
\end{abstract}

Palavras-chave: planta aquática, planta daninha, crescimento, nutrientes.

ABSTRACT - This research aimed to study the biomass and nutrient distribution among the vegetative components of Heteranthera reniformis under the effect of different concentrations of $N$, $P$ and $K$. The plants were cultivated in plastic pots filled with rolled stone, in nutrient solutions with $80 \%$ of the original concentration of Sarruge as the base solution. The experimental design was completely randomized, at 5 levels $(0,25,50,75 \%$ of the base solution) evaluated individually in $N, P$ and $K$, besides the control (100\% of the base solution), with 4 replicates in the period of 35 days. The largest leaf areas were verified in solutions to $75 \%$ of $P$ and $50 \%$ of $N$ and $K$. The solution up to $50 \%$ of $N$ provided the largest dried biomass of the plants. The stem contribution to the allocation of resources presented results ranging from 55.5 to $74.5 \%$ in relation to the total dry matter regarding level $O$ and $75 \%$ of $N$. Root contribution decreased with the increase of $N$, $P$ and $K$ concentrations. The greatest root contributions were in the absence of $N(26.8 \%)$ and $P(19.2 \%)$, which were higher in relation to their respective more concentrated levels. The contents of $N, P$ and $K$ corresponded to an increasing order in leaf, stem and roots, with the largest contents obtained in the range of 50 to $125 \mathrm{mg} \mathrm{L}^{-1}$ of $\mathrm{N}$; 5 to $15 \mathrm{mg} \mathrm{L}^{-1}$ of P; and 100 to $150 \mathrm{mg} \mathrm{L}^{-1}$ of $K$.

Keywords: aquatic plant, weed, growth, nutrients.

1 Recebido para publicação em 24.8.2004 e na forma revisada em 21.4.2005.

Parte da dissertação do primeiro autor apresentada para a obtenção do título de Mestre.

2 Eng.-Agr., M.S. FCA-UNESP, Caixa Postal 237, 18603-970 Botucatu-SP; ${ }^{3}$ Professor Dr., Departamento de Produção Vegetal, FCA/UNESP. ${ }^{4}$ Aluno de graduação de Engenharia Agronômica, FCA/UNESP. 


\section{INTRODUÇÃO}

Nos ambientes aquáticos, os nutrientes estão acumulados nos sedimentos das regiões mais profundas dos corpos hídricos, sendo regenerados e liberados à zona de produção. Esse sistema possui alta capacidade para solubilizar compostos orgânicos e inorgânicos distribuídos em gradientes, além de estar associado a fatores como luz, temperatura e gases (Rickelefs, 1996).

As plantas aquáticas possuem diferentes graus de colonização, com ampla adaptação a diversas condições ambientais. O rápido crescimento populacional dessas plantas e as elevadas produções de biomassa favorecem a ocupação de vastas áreas, podendo afetar a múltipla utilização da água. Entre os problemas mais freqüentes incluem-se redução na produção de peixes, esportes aquáticos, navegação, irrigação e produção de energia hidrelétrica (Esteves, 1998).

As plantas aquáticas conferem autonomia ao ambiente aquático, pois representam a base da organização do sistema através da produção de biomassa, que, ao se decompor, promove uma liberação maciça de nutrientes inorgânicos e matéria orgânica dissolvida. As taxas de liberação são influenciadas pela dinâmica populacional das plantas, pela sua mortalidade durante e após o crescimento e pelas condições ambientais (Rickelefs, 1996).

Segundo Esteves (1998), o aumento populacional desordenado dessas plantas deve-se principalmente à falta de predadores e ao aumento do nível de eutrofização do ambiente.

Alguns estudos relacionam a ocorrência de plantas aquáticas como Phragmites australis, Typha latifolia e Hydrocotyle vulgaris, entre outras espécies, com as condições ambientais, com o intuito de identificar os fatores que propiciam o desenvolvimento desordenado de determinada espécie (Petrucio \& Esteves, 2000; Baattrup-Pedersen et al., 2003; Petticrew et al., 2003; Amoros et al., 2000; Reddy \& Tucker, 1983).

Khedr \& El-demerdash (1997) estudaram a relação entre plantas aquáticas e o ambiente, em canais de irrigação e drenagem, classificando a vegetação em sete grupos de ocorrência. Os autores verificaram quais grupos de plantas submersas apresentavam menor diversidade de espécies e dominância, sendo mais afetadas pelo sombreamento das árvores na margem do canal do que emersas e flutuantes.

De acordo com os autores, as variáveis ambientais que apresentaram correlação significativa com o crescimento de espécies dominantes foram: sombreamento, largura do canal, condutividade elétrica e concentração do íon potássio na água.

O estudo da biologia de plantas aquáticas emersas, como Myriophyllum aquaticum e Ludwigia peploides, realizado por Rejmankova (1992), demonstrou rápido crescimento, alto acúmulo de nitrogênio, maior alocação de biomassa e nitrogênio nas raízes e rápida decomposição. Estas plantas desenvolveram-se bem, submetidas a uma ampla faixa de concentração de $\mathrm{N}$ adicionado à água (20 - 140 mg de $\left.\mathrm{NO}_{3} \mathrm{~L}^{-1}\right)$.

A importância vital do nitrogênio está relacionada à constituição de aminoácidos, proteínas, atividade enzimática, assim como sintese de clorofila (Marschner, 1990; Malavolta et al., 1989).

Em plantas herbáceas, o nitrogênio pode ser translocado por meio de compostos como glutamina, asparagina, glutamato e $\mathrm{NO}_{3}$, ocorrendo alterações no teor de $\mathrm{N}$ em raízes, caules e folhas. Essas alterações refletem a alocação de nutrientes na planta de acordo com a demanda no estágio de desenvolvimento em que a planta se encontra (Salisbury $\&$ Ross, 1992).

De acordo com alguns autores, o princípio da alocação de biomassa está condicionado aos recursos limitados do meio, os quais resultam em habilidades de competição, como crescimento, sobrevivência e reprodução (BarratSegretain, 2001).

Além dessses fatores, o tipo de vegetação também influencia a decomposição, bem como a liberação de nutrientes e compostos orgânicos, sendo ela mais acelerada nas plantas aquáticas submersas e de folhas flutuantes quando comparada às emersas (Wetzel, 1993). Contudo, o crescimento excessivo de plantas aquáticas tem causado sérios problemas, 
citados anteriormente, que motivaram a realização de mais estudos.

No entanto, são escassos estudos referentes à absorção de nutrientes e crescimento de $H$. reniformis, considerada planta daninha importante em áreas de arroz irrigado e canais de irrigação (Vasconcelos et al., 1999; Ferrero, 1996; Vescovi et al., 1996).

Heteranthera reniformis é uma planta aquática da família Pontederiaceae, possuindo alguns nomes populares, como agriãozinho aquático, hortelã-do-brejo, pavoa, aguapémirim, entre outros, nativa de regiões de clima tropical e subtropical das Américas e África. No Brasil, apresenta ampla distribuição em quase todo o território. Considerada planta perene e herbácea, adapta-se tanto à água quanto a solos úmidos. Desenvolve-se inicialmente a partir da semente, que germina apenas em solo saturado de água, após o que ocorre o enraizamento.

Entretanto, quando aumenta o nivel da água, a planta se desprende e flutua. Possui como meio de reprodução predominante a propagação vegetativa, por meio da qual se originam grandes conjuntos de plantas, podendo formar extensos tapetes flutuantes, (Kissmann \& Groth, 1997).

Em razão de esta espécie possuir elevada capacidade de colonização em condições favoráveis, torna-se necessário conhecer seu desenvolvimento para subsidiar medidas preventivas de controle. Assim, o objetivo deste trabalho foi estudar a distribuição de biomassa, o crescimento e a alocação de nutrientes nos órgãos da planta de $H$. reniformis em casa de vegetação.

\section{MATERIAL E MÉTODOS}

O experimento foi instalado em casa de vegetação, no Núcleo de Pesquisas Avançadas em Matologia (NUPAM) do Departamento de Produção Vegetal da FCA/UNESP, campus de Botucatu-SP.

As mudas foram obtidas em um canal de drenagem na várzea, localizado na Fazenda Edgardia, pertencente à UNESP, campus de Botucatu. Foram selecionadas mudas com três folhas, para o plantio. Utilizaram-se vasos plásticos $(13,8 \times 28,3 \times 11,8 \mathrm{~cm}$ de largura, comprimento e altura, respectivamente) de 4,5 litros, totalizando uma área de superficie aproximada de $0,04 \mathrm{~m}^{2}$, contendo 0,5 litro de pedras roladas lavadas com água destilada.

Nesse substrato foi realizado o plantio de uma muda (lavada com água destilada), sendo adicionado 0,5 litro de solução nutritiva (Tabela 1).

Tabela 1 - Composição química da solução de Sarruge (1975) a $80 \%$ da concentração original, que corresponde à solução-base utilizada no experimento

\begin{tabular}{|c|c|}
\hline Nutriente & Concentração $\left(\mathrm{mg} \mathrm{L}^{-1}\right)$ \\
\hline $\mathrm{N}$ & 168,0 \\
\hline $\mathrm{P}$ & 24,8 \\
\hline $\mathrm{K}$ & 187,2 \\
\hline $\mathrm{Ca}$ & 160,0 \\
\hline $\mathrm{Mg}$ & 38,4 \\
\hline S & 51,2 \\
\hline $\mathrm{Fe}$ & 4,0 \\
\hline $\mathrm{B}$ & 0,4 \\
\hline $\mathrm{Mn}$ & 0,4 \\
\hline $\mathrm{Zn}$ & 0,04 \\
\hline $\mathrm{Cu}$ & 0,0016 \\
\hline Mo & 0,0008 \\
\hline
\end{tabular}

As soluções nutritivas foram mantidas com aeração constante por um sistema de mangueiras e registros interligados a compressores de ar, sendo renovadas a cada três dias, bem como lavado o substrato com água destilada. Os sais usados no preparo das soluções-estoque na concentração de $1 \mathrm{M}$ foram: $\mathrm{KH}_{2} \mathrm{PO}_{4}, \mathrm{KNO}_{3}, \mathrm{Ca}\left(\mathrm{NO}_{3}\right)_{2}, \mathrm{MgSO}_{4}, \mathrm{KCl}$ $\mathrm{CaCl}_{2}, \mathrm{NH}_{4} \mathrm{H}_{2} \mathrm{PO}_{4}, \mathrm{NH}_{4} \mathrm{NO}_{3},\left(\mathrm{NH}_{4}\right)_{2} \mathrm{SO}_{4} \mathrm{e}$ $\mathrm{Mg}\left(\mathrm{NO}_{3}\right)_{2}$. No preparo da solução de micronutrientes foram utilizados $\mathrm{H}_{3} \mathrm{BO}_{3}(2,86 \mathrm{~g})$, $\mathrm{MnCl}_{2} \cdot 4 \mathrm{H}_{2} \mathrm{O}(1,81 \mathrm{~g}), \mathrm{ZnCl}_{2}(0,10 \mathrm{~g}), \mathrm{CuCl}_{2}$ $(0,04 \mathrm{~g})$ e $\mathrm{H}_{2} \mathrm{MoO}_{4} \cdot \mathrm{H}_{2} \mathrm{O}(0,02 \mathrm{~g})$, sendo diluídos em água destilada; em seguida, o volume foi completado para 1 litro em balão volumétrico.

A solução de Fe-EDTA foi obtida por dissolução de 26,2 g de EDTA dissódico (etileno diamino tetra acetato de sódico) e 24,0 g de $\mathrm{FeSO}_{4} \cdot 7 \mathrm{H}_{2} \mathrm{O}$ separadamente em água destilada, os quais foram posteriormente misturados.

A solução foi areada com o auxílio de um compressor de ar por um período de 12 horas. 
Em seguida, esta solução foi filtrada em filtro de papel, sendo o volume completado para 1 litro em balão volumétrico, e armazenada em frasco de vidro escuro, tampado e acondicionado em câmara fria.

Antes da instalação do experimento definitivo, foi realizado um ensaio preliminar para determinar a concentração de nutrientes da solução de Sarruge (1975) mais próxima dos níveis adequados à espécie - esta solução foi utilizada como testemunha no experimento.

Nesse ensaio foram utilizadas cinco diluições, correspondentes a 20, 40, 60, 80 e 100\% da solução de Sarruge (1975), além de uma testemunha constituída por água destilada, as quais foram padronizadas a $\mathrm{pH}$ 6,5 através da adição de $\mathrm{HCl}$ ou $\mathrm{NaOH}$. O delineamento experimental utilizado foi o inteiramente ao acaso, com seis tratamentos e quatro repetições, por um período de 32 dias. As variáveis analisadas para esse ensaio preliminar foram: área foliar, número de folhas e biomassa seca (folha, caule, raiz e total).

A fim de manter as concentrações iniciais de nutrientes durante o intervalo de troca da solução, foram realizadas reposições do volume com água destilada, conforme a evaporação de cada vaso, através do nível marcado com grafite em uma plaqueta colada na lateral do vaso.

Com base nos resultados, selecionou-se a solução nutritiva que propiciou condições próximas à demanda nutricional ótima da espécie. Verificou-se que a diluição a $80 \%$ da solução de Sarruge proporcionou maior desenvolvimento da planta para a maioria das variáveis analisadas. Esta solução foi denominada de solução-base, à qual foram aplicados individualmente os diferentes niveis de cada nutriente.

O estudo definitivo foi conduzido durante 35 dias nas mesmas instalações, usando os mesmos procedimentos de montagem e biometria do ensaio anterior. O delineamento experimental utilizado foi o inteiramente ao acaso, com quatro níveis da solução de Sarruge $(0,25,50$ e $75 \%$ da solução-base) avaliados individualmente em N, P e K, além da testemunha (correspondente a $100 \%$ da soluçãobase), com quatro repetições.
Os parâmetros avaliados constituíram-se de área foliar, biomassa seca e teor de nutrientes na folha, no caule, na raiz e total.

A concentração dos nutrientes nas soluções variou entre niveis de $\mathrm{N}(0,42,84,126 \mathrm{e}$ $\left.168 \mathrm{mg} \mathrm{L}^{-1}\right), \mathrm{P}\left(0 ; 6,2 ; 12,4 ; 18,6 ;\right.$ e $\left.24,8 \mathrm{mg} \mathrm{L}^{-1}\right)$ e K $\left(0 ; 46,8 ; 93,6 ; 140,4 ;\right.$ e $\left.187,2 \mathrm{mg} \mathrm{L}^{-1}\right)$, sendo preservada a concentração dos demais nutrientes com o balanceamento químico. As soluções nutritivas foram renovadas a cada três dias, sendo lavado o substrato com água destilada.

A determinação dos nutrientes $(\mathrm{N}, \mathrm{P}, \mathrm{K})$ nas diferentes partes da planta foi feita no Laboratório de Relação Solo/Planta do Departamento de Produção Vegetal da FCAUnesp/Botucatu.

Para a determinação dos teores de $\mathrm{P}$ e K, o material vegetal foi digerido em uma mistura de ácido nitro-perclórico, sendo, para o $\mathrm{N}$, submetido à digestão sulfúrica, seguindo metodologia proposta por Malavolta et al. (1989). A determinação de $\mathrm{N}$ foi realizada por titulometria, enquanto os outros macronutrientes foram determinados por espectrometria de plasma.

Os resultados obtidos foram submetidos à análise de variância pelo teste $\mathrm{F}$ e a comparação de médias foi feita pelo teste t a $5 \%$ de probabilidade. As análises de regressão foram realizadas com as médias, com o auxílio do programa Jandel Sigma Stat 2.0, sendo apresentadas apenas as regressões que foram significativas (Tabelas 4 e 5).

\section{RESULTADOS E DISCUSSÃO}

Na Tabela 2 estão apresentados os resultados de área foliar e biomassa seca total observados em plantas de H. reniformis. Quanto à área foliar, verificou-se que entre os niveis de $\mathrm{N}$ as soluções referentes a 50 e $75 \%$ (84 e $126 \mathrm{mg} \mathrm{L}^{-1}$ ) foram semelhantes à solução completa (100\%), não diferindo estatisticamente. A adição de niveis crescentes de $\mathrm{N}$ propiciou aumento linear na área foliar (Figura 1).

Em relação aos níveis de fósforo, também houve aumento linear e crescente na área foliar com o incremento do nutriente na solução (Figura 2). Para os níveis de potássio, foram observadas diferenças na resposta em área 
Tabela 2 - Efeito de diferentes concentrações de N, P e K sobre a área foliar e biomassa seca total de Heteranthera reniformis

\begin{tabular}{|c|c|c|c|c|c|c|}
\hline \multirow{2}{*}{ Tratamento } & \multicolumn{3}{|c|}{ Área foliar $\left(\mathrm{cm}^{2}\right)$} & \multicolumn{3}{|c|}{ Biomassa seca total $\left(\mathrm{g}\right.$ vaso $\left.^{-1}\right)$} \\
\hline & $\mathrm{N}$ & $\mathrm{P}$ & $\mathrm{K}$ & $\mathrm{N}$ & $\mathrm{P}$ & $\mathrm{K}$ \\
\hline $0 \%$ & $34,25 \mathrm{~d}$ & $90,50 \mathrm{c}$ & $376,75 \mathrm{~b}$ & $0,335 \mathrm{c}$ & $0,762 \mathrm{~b}$ & $1,063 \mathrm{a}$ \\
\hline $25 \%$ & $299,50 \mathrm{c}$ & $366,75 \mathrm{~b}$ & $307,50 \mathrm{~b}$ & $2,248 \mathrm{~b}$ & $2,109 \mathrm{a}$ & $1,517 \mathrm{a}$ \\
\hline $50 \%$ & $567,75 \mathrm{a}$ & $379,25 \mathrm{ab}$ & $512,50 \mathrm{a}$ & $3,573 \mathrm{a}$ & $1,939 \mathrm{ab}$ & $2,449 \mathrm{a}$ \\
\hline $75 \%$ & $486,45 \mathrm{a}$ & $465,50 \mathrm{ab}$ & $334,50 \mathrm{~b}$ & $3,770 \mathrm{a}$ & $2,792 \mathrm{a}$ & $1,878 \mathrm{a}$ \\
\hline $100 \%$ & $508,25 \mathrm{a}$ & $508,25 \mathrm{a}$ & $508,25 \mathrm{a}$ & $2,405 \mathrm{~b}$ & $2,405 \mathrm{a}$ & $2,405 \mathrm{a}$ \\
\hline Teste $\mathrm{F}$ & $68,8 * *$ & $19,7 * *$ & $17,3 * *$ & $47,97 * *$ & $3,57^{*}$ & $1,0^{*}$ \\
\hline $\mathrm{CV}(\%)$ & 18,1 & 29,3 & 24,7 & 17,32 & 35,03 & 52,25 \\
\hline d.m.s & 86,4 & 133,4 & 126,3 & 0,59 & 1,27 & 1,2 \\
\hline
\end{tabular}

Médias seguidas de mesma letra, na coluna, não diferem estatisticamente entre si pelo teste " $t$ "a $5 \%$ de probabilidade.

** Significativo pelo teste $\mathrm{F}$ a $1 \%$ de probabilidade e * significativo pelo teste $\mathrm{F}$ a $5 \%$ de probabilidade.

foliar, porém não foi possivel ajustar a um modelo que indica a ausência de correlação entre área foliar e niveis de $\mathrm{K}$ na solução (Figura 3).

As condições mais favoráveis ao desenvolvimento da planta com base na área foliar ocorreram em soluções de $50 \%$ de $\mathrm{N}$ e $\mathrm{K}$, bem como na testemunha com $100 \%$ de N, P e K, os quais propiciaram as maiores áreas foliares $(\mathrm{N}=567,75 ; \mathrm{K}=512,5$; testemunha= $508,25 \mathrm{~cm}^{2}$, respectivamente).

Observou-se que o caule respondeu aos diferentes niveis de $\mathrm{N}$; a partir de $100 \mathrm{mg} \mathrm{L}^{-1}$ pode ser identificado o efeito tóxico das doses, uma vez que folha e raiz mantiveram-se constantes (Figura 4).

Verificou-se também que a resposta do caule sob diferentes niveis de $\mathrm{P}$ foi ajustada adequadamente, indicando que o nivel ótimo

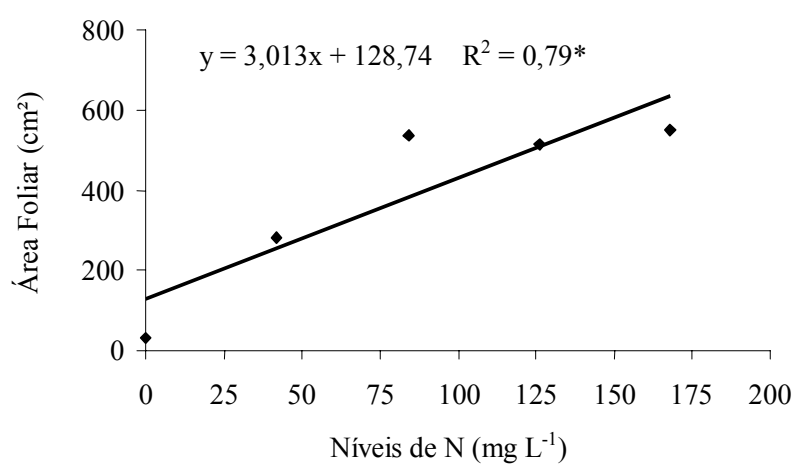

Figura 1 - Área foliar de Heteranthera reniformis em função dos níveis de nitrogênio aos 35 dias após transplante. de P está entre 10 e $15 \mathrm{mg} \mathrm{L}^{-1}$ (Figura 5), ao passo que entre os niveis de $\mathrm{K}$ não houve ajuste significativo em relação à biomassa das partes da planta (Figura 6).

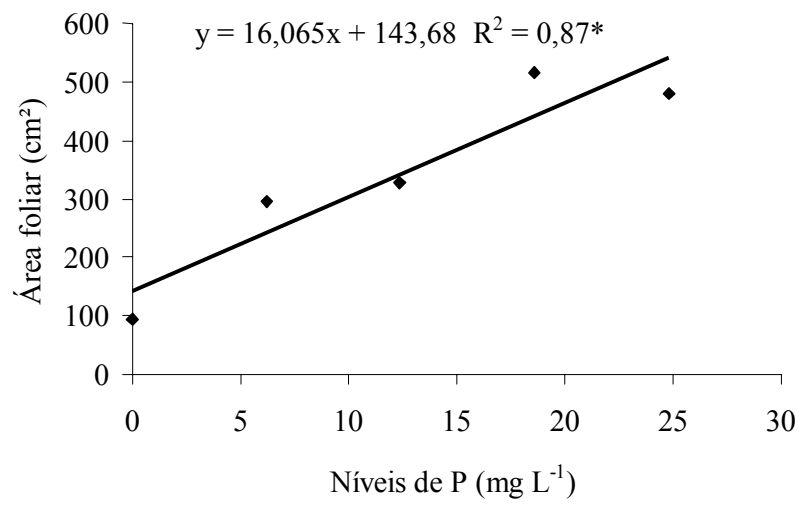

Figura 2 - Área foliar de Heteranthera reniformis em função dos níveis de fósforo aos 35 dias após transplante.

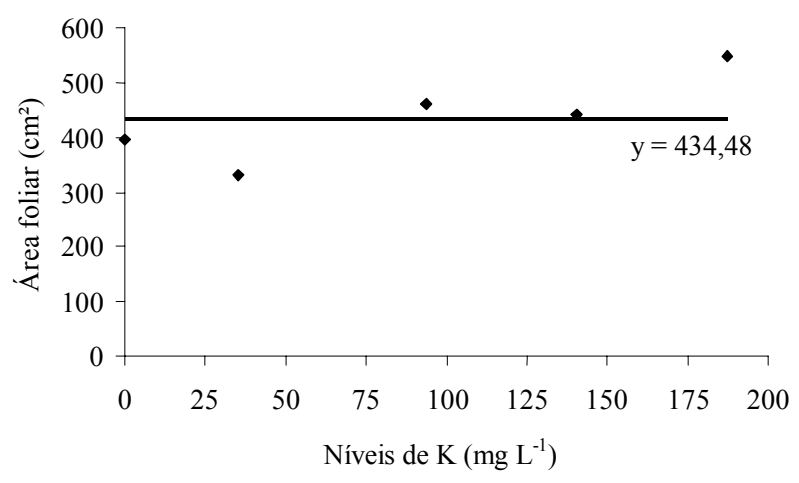

Figura 3 - Área foliar de Heteranthera reniformis em função dos níveis de potássio aos 35 dias após transplante.

Planta Daninha, Viçosa-MG, v. 23, n. 1, p. 33-42, 2005 


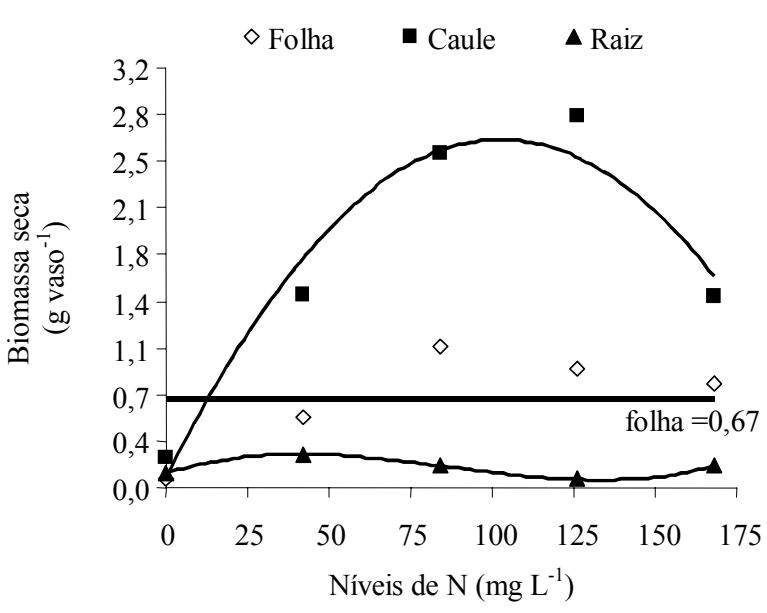

Figura 4 - Biomassa seca de folha, caule e raiz de Heteranthera reniformis sob o efeito de diferentes níveis de $\mathrm{N}$.

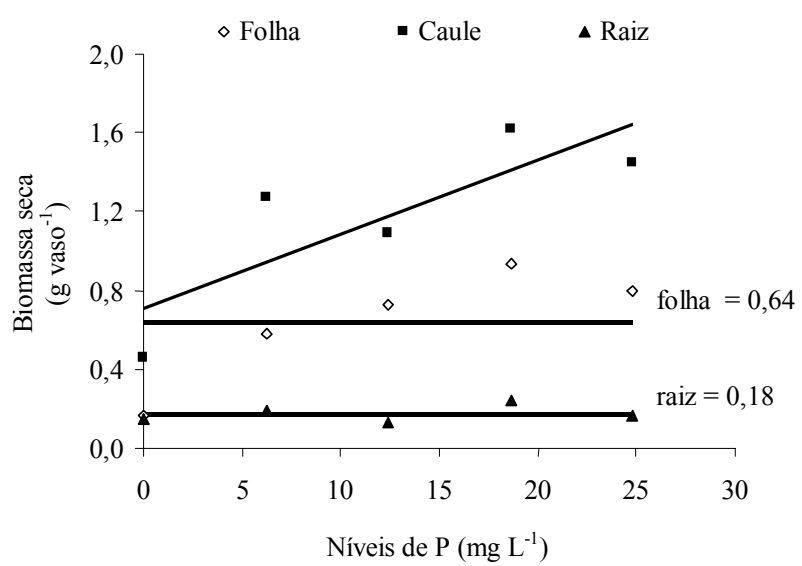

Figura 5 - Biomassa seca de folha, caule e raiz de Heteranthera reniformis sob o efeito de diferentes níveis de $\mathrm{P}$.

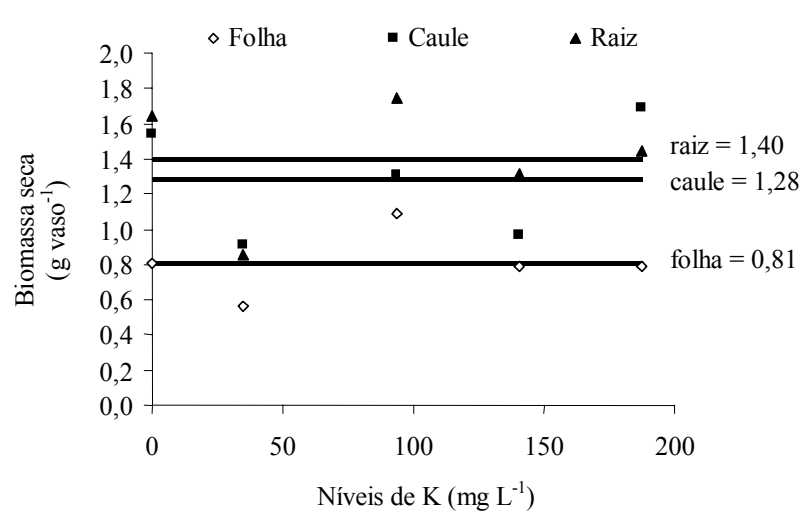

Figura 6 - Biomassa seca de folha, caule e raiz de Heteranthera reniformis sob o efeito de diferentes níveis de $\mathrm{K}$.
Quanto à biomassa seca de folhas (Tabela 3 e Figura 4), notou-se que os incrementos foram crescentes com a adição de $\mathrm{N}$ até $50 \%$. $\mathrm{O}$ tratamento a $0 \%$ de $\mathrm{N}$ permitiu inferir que a ausência deste nutriente pode ser prejudicial ao desenvolvimento da planta. Isso confirma a importância vital do nitrogênio, relacionada à constituição de aminoácidos, proteínas, atividade enzimática, assim como sintese de clorofila (Malavolta et al., 1989).

Petruccio \& Esteves (2000) relataram a importância da relação N:P na água como fator que interfere na capacidade de absorção de plantas aquáticas, a exemplo de Eichhornia crassipes, que apresenta maior produção de biomassa entre razões N:P na água de 2,3 e 5 (Reddy \& Tucker, 1983). As concentrações de $\mathrm{N}$ e P utilizadas nas soluções do presente estudo condicionaram a razões $\mathrm{N}: \mathrm{P}$ de 1,6 a 6,8 . Portanto, $H$. reniformis condicionada a razões $\mathrm{N}: \mathrm{P}$ na água acima de 5,1 pode resultar na redução da absorção, caso a capacidade de saturação na absorção de nutrientes já tenha ocorrido. A conseqüência desse fato pode ser a limitação do crescimento, que não responderá em igual proporção aos incrementos de $\mathrm{N}$.

Quanto à biomassa total de $H$. reniformis, verificou-se que as soluções nutritivas a 50 e $75 \%$ de $\mathrm{N}$ não diferiram entre si, porém elas propiciaram os maiores valores $(3,573$ e

Tabela 3 - Distribuição percentual da biomassa seca das diferentes partes da planta de Heteranthera reniformis, sob diferentes níveis de $\mathrm{N}, \mathrm{P}$ e $\mathrm{K}$, em comparação ao início do experimento e ao cultivo em água destilada

\begin{tabular}{|l|c|c|c|c|c|}
\hline \multirow{2}{*}{ Estrutura } & \multicolumn{5}{|c|}{ Níveis de N (\%) } \\
\cline { 2 - 6 } & $0^{1 /}$ & 25 & 50 & 75 & 100 \\
\hline Folha & 17,9 & 23,4 & 28,5 & 23,8 & 33,0 \\
\hline Caule & 55,5 & 65,3 & 67,1 & 74,5 & 60,2 \\
\hline Raiz & 26,8 & 11,3 & 4,4 & 1,7 & 6,8 \\
\hline & \multicolumn{5}{|c|}{ Níveis de P (\%) } \\
\hline Folha & 21,5 & 28,3 & 37,3 & 33,4 & 33,0 \\
\hline Caule & 59,4 & 62,3 & 56,2 & 57,9 & 60,2 \\
\hline Raiz & 19,2 & 9,4 & 6,5 & 8,7 & 6,8 \\
\hline & \multicolumn{5}{|c|}{ Níveis de K (\%) } \\
\hline Folha & 31,3 & 37,1 & 36,1 & 36,2 & 33,0 \\
\hline Caule & 63,4 & 56,6 & 57,8 & 60,1 & 60,2 \\
\hline Raiz & 5,2 & 6,2 & 6,1 & 3,7 & 6,8 \\
\hline
\end{tabular}

$1 / 0,25,50,75$ e 100 correspondem às porcentagens do nutriente na solução-base. 
3,770 g, respectivamente) (Tabela 2). Esta biomassa apresentou uma tendência quadrática, que permitiu conferir a faixa de concentração de $\mathrm{N}$ ótima para a espécie, a qual está entre 70 e $100 \mathrm{mg} \mathrm{L}^{-1}$ de $\mathrm{N}$ (Figura 7).

Garrard \& Haller (1981) avaliaram os efeitos de concentrações de $\mathrm{N}\left(0 \mathrm{a} 10 \mathrm{mg} \mathrm{L}^{-1}\right)$ em tanques contendo $10 \%$ da solução de Hoagland (1950) na produtividade de Eichhornia crassipes, representante da mesma família de $H$. reniformis, e constataram que quatro semanas de cultivo na concentração de $2,25 \mathrm{mg} \mathrm{L}^{-1}$ de nitrogênio foi o suficiente para a produtividade máxima de $30 \mathrm{~g}$ de massa seca. Em relação aos resultados obtidos, pôde-se estimar a produtividade máxima de biomassa seca total baseada em 94,3 g.m ${ }^{-2}$ durante 35 dias, resultando em $2,7 \mathrm{~g} \mathrm{~m}^{-2} \mathrm{dia}^{-1} \mathrm{com} \mathrm{a}$ adição de $84 \mathrm{mg}$ de nitrogênio por litro (50\% da solução-base). Isso permite inferir que

Tabela 4 - Equações de regressão da biomassa seca nas diferentes partes da planta de Heteranthera reniformis sob o efeito dos níveis do nutriente correspondente

\begin{tabular}{|c|l|c|}
\hline Estrutura & \multicolumn{1}{|c|}{ Equação de regressão } & $\mathrm{R}^{2}$ \\
\hline \multicolumn{3}{|c|}{ Nitrogênio } \\
\hline Caule & $\mathrm{y}=-0,0002 \mathrm{x}^{2}+0,0497 \mathrm{x}+0,0835$ \\
\hline Raiz & $\mathrm{y}=0,0000005 \mathrm{x}^{3}-0,0001 \mathrm{x}^{2}+0,008 \mathrm{x}+0,109$ & $0,949^{*}$ \\
\hline Planta & $\mathrm{y}=-0,0003 \mathrm{x}^{2}+0,0671 \mathrm{x}+0,2833$ & $0,99^{* *}$ \\
\hline \multicolumn{3}{|c|}{ Fósforo } \\
\hline Folha & $\mathrm{y}=0,0259 \mathrm{x}+0,317$ & $0,982^{*}$ \\
\hline
\end{tabular}

** Significativo pelo teste $\mathrm{F}$ a $1 \%$ de probabilidade; e * significativo pelo teste $\mathrm{F}$ a $5 \%$ de probabilidade.

Tabela 5 - Equações de regressão dos teores de N, P e K nas diferentes partes da planta de Heteranthera reniformis sob o efeito dos níveis do nutriente correspondente

\begin{tabular}{|c|c|c|}
\hline Estrutura & Equação de regressão & $\mathrm{R}^{2}$ \\
\hline \multicolumn{3}{|c|}{ Nitrogênio } \\
\hline Caule & $\mathrm{y}=0,112 \mathrm{x}+22,568$ & $0,805^{* *}$ \\
\hline \multicolumn{3}{|c|}{ Fósforo } \\
\hline Folha & $\mathrm{y}=-0,0243 \mathrm{x}^{2}+0,635 \mathrm{x}+2,271$ & $0,980^{*}$ \\
\hline Caule & $\mathrm{y}=0,174 \mathrm{x}+2,542$ & $0,820^{*}$ \\
\hline Raiz & $\mathrm{y}=0,0613 \mathrm{x}+1,096$ & $0,988^{* *}$ \\
\hline \multicolumn{3}{|c|}{ Potássio } \\
\hline Caule & $\mathrm{y}=0,209 \mathrm{x}+33,403$ & $0,772^{*}$ \\
\hline Planta & $\mathrm{y}=0,284 \mathrm{x}+44,975$ & $0,939^{* *}$ \\
\hline
\end{tabular}

** Significativo pelo teste $\mathrm{F}$ a $1 \%$ de probabilidade; e * significativo pelo teste $\mathrm{F}$ a $5 \%$ de probabilidade.
$H$. reniformis pode ser considerada menos agressiva do que Eichhornia crassipes, visto que a sua produtividade de biomassa diária foi dez vezes menor, embora cultivada em maior concentração de $\mathrm{N}$.

A ausência de $\mathrm{N}$ e $\mathrm{P}$ (Figuras 7 e 8, respectivamente) afetou a produção de biomassa total significativamente.

Quanto ao N, houve incrementos crescentes com o aumento da concentração até $50 \%$; a partir de $126 \mathrm{mg} \mathrm{L}^{-1}$ houve tendência de efeito tóxico na biomassa total. Entretanto, entre os niveis de $\mathrm{P}$ não ocorreram diferenças entre 25, 50, 75 e 100\% (Tabela 2). Já entre os niveis de $\mathrm{K}$ não foram observadas diferenças significativas (Figura 9 e Tabela 2).

Embora os niveis de $\mathrm{P}$ e $\mathrm{K}$ não tenham sido ajustados a um modelo, de maneira geral, pode-se inferir que o nivel ótimo de $\mathrm{P}$ está entre 5 e $15 \mathrm{mg} \mathrm{L}^{-1}$ (Figuras 8 e 9).

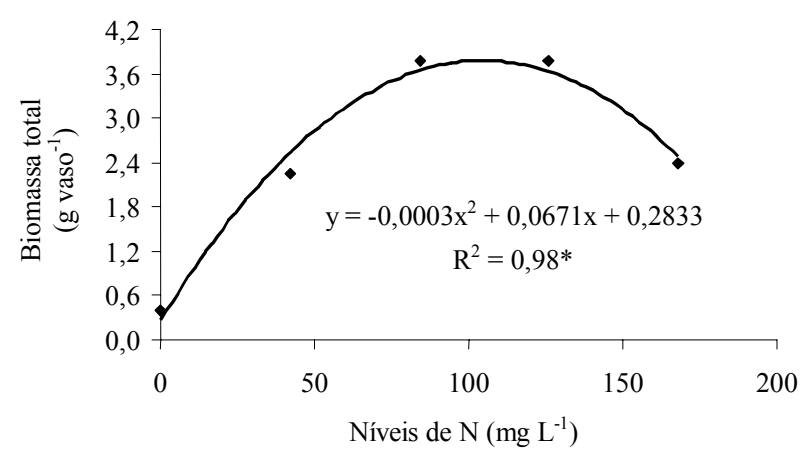

Figura 7 - Biomassa seca total de Heteranthera reniformis sob o efeito de diferentes níveis de $\mathrm{N}$.

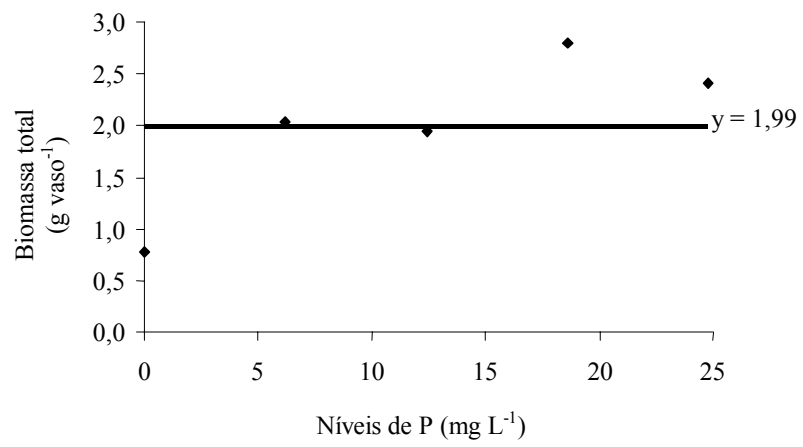

Figura 8 - Biomassa seca total de Heteranthera reniformis sob o efeito de diferentes níveis de $\mathrm{P}$.

Planta Daninha, Viçosa-MG, v. 23, n. 1, p. 33-42, 2005 


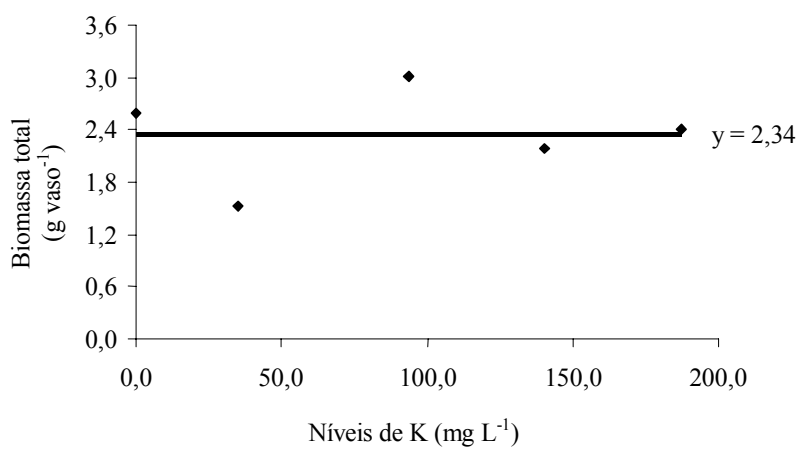

Figura 9 - Biomassa seca total de Heteranthera reniformis sob o efeito de diferentes níveis de $\mathrm{K}$.

A biomassa seca de caules apresentou comportamento constante sob o efeito das concentrações de macronutrientes (Tabela 3). Pôde-se ressaltar a importante contribuição dos caules, que representaram a maior proporção de biomassa seca em relação à biomassa total produzida pela planta. Esse comportamento pode estar relacionado à função fotossintética do caule, que apresenta pigmentos verdes associados, e, provavelmente, à melhor utilização dos nutrientes em relação a gastos metabólicos na formação de biomassa (Salisbury \& Ross, 1992). Observou-se maior incremento na biomassa dos caules de $H$. reniformis a $75 \%$ de nitrogênio. Verificouse, ainda, incremento desta biomassa com o aumento dos niveis de $\mathrm{N}$ e $\mathrm{P}$, exceto para o $\mathrm{K}$.

De maneira geral, observou-se que houve redução na contribuição de biomassa de raízes (Tabela 3) com o aumento da concentração de $\mathrm{N}$ e P. O cultivo em soluções com a ausência de $\mathrm{N}$ e $\mathrm{P}$ propiciou maiores proporções $(26,8$ e $19,2 \%$, respectivamente) de biomassa de raízes em relação aos seus respectivos niveis mais concentrados.

Esses resultados demonstram que $H$. reniformis, nas condições testadas, destina grande parte dos fotoassimilados para a produção de raízes quando na ausência dos nutrientes essenciais para o seu desenvolvimento, como $\mathrm{N}$ e P. Esse fato permite refletir sobre o potencial agressivo da espécie, que, em condições nutricionais adversas, prioriza a produção de biomassa em órgãos que possam garantir a sobrevivência.

De acordo com alguns autores, o princípio da alocação de biomassa está condicionado aos recursos limitados do meio, os quais resultam em habilidades de competição, como crescimento, sobrevivência e reprodução (BarratSegretain, 2001).

A alocação de biomassa nas folhas apresentou amplitude que variou entre 17,9 e $37,3 \%$ em relação ao total de biomassa seca produzida pela planta, referentes ao nível 0\% de $\mathrm{N}$ e $50 \%$ de $\mathrm{P}$, respectivamente.

Na Figura 10 estão apresentados os teores de nitrogênio no caule, na folha e na raiz sob o efeito dos niveis de N. Observou-se que os teores no caule e na raiz apresentaram comportamento semelhante em função do incremento de $\mathrm{N}$ na solução. Em relação às folhas, os maiores teores ocorreram a 0 e $25 \%$ de $\mathrm{N}$ (42 $\mathrm{mg} \mathrm{L}^{-1}$ de $\mathrm{N}$ ), sendo importante ressaltar que a planta respondeu aos demais niveis, embora em menores proporções. Esse fato pode estar relacionado ao ambiente de coleta das plantas, definido como várzea, o qual se caracteriza pelo elevado teor de matéria orgânica (compostos nitrogenados), influenciando o teor de $\mathrm{N}$ da plântula. Associado a esse fator, podese destacar que o maior desenvolvimento da planta pode ter reduzido os teores em função da maior demanda, a exemplo da concentração de $84 \mathrm{mg} \mathrm{L}^{-1}$ de $\mathrm{N}$, que propiciou condições mais favoráveis ao crescimento.

Em relação ao ajuste linear do teor de $\mathrm{N}$ apresentado no caule e à redução ocorrida na folha a partir de $84 \mathrm{mg} \mathrm{L}^{-1}$, concluiu-se que houve alteração na alocação de $\mathrm{N}$ na planta, com a possivel translocação deste nutriente

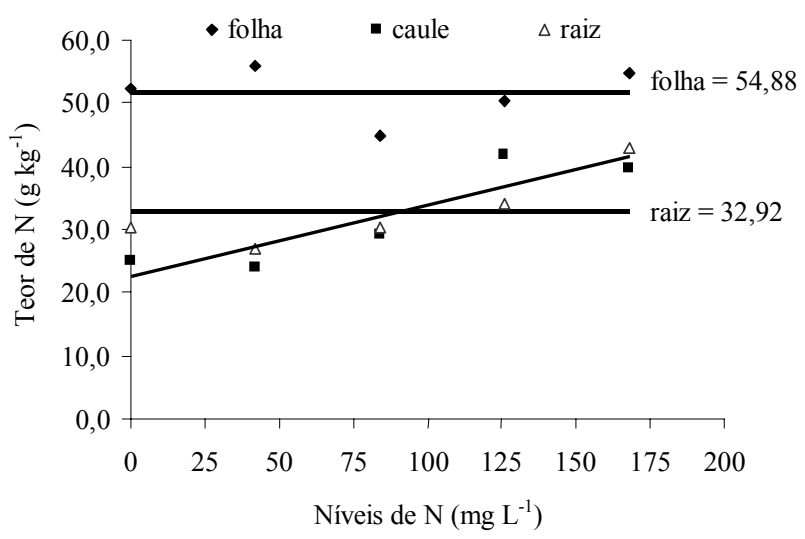

Figura 10 - Teor de nitrogênio em diferentes partes da planta de Heteranthera reniformis em função dos níveis de nitrogênio aos 35 dias após transplante. 
para o caule, uma vez que as flores desta espécie são originadas na inserção do pecíolo da folha com o caule em forma de cachos. Isso pode ser explicado pelo fenômeno que ocorre em plantas herbáceas, em que há uma transferência do $\mathrm{N}$ na forma de aminoácidos, os quais são destinados à síntese de proteína para outras partes da planta, dependendo do estágio de desenvolvimento, para desenvolver outras estruturas reprodutivas ou vegetativas (Salisbury \& Ross, 1992).

Verificou-se que os teores de fósforo na folha e no caule foram semelhantes até $5 \mathrm{mg} \mathrm{L}^{-1}$ (Figura 11); a partir deste nivel a folha apresenta incrementos crescentes com a adição de $\mathrm{P}$ à solução até $15 \mathrm{mg} \mathrm{L}^{-1}$. Acima desta concentração, observou-se um desvio na alocação de $\mathrm{P}$, em virtude da redução significativa

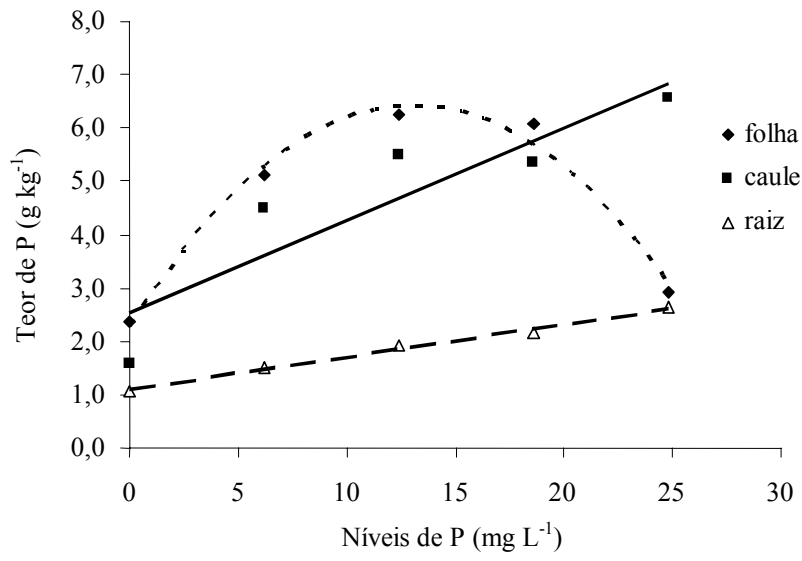

Figura 11 - Teor de fósforo em diferentes partes da planta de Heteranthera reniformis em função dos níveis de fósforo aos 35 dias após transplante.

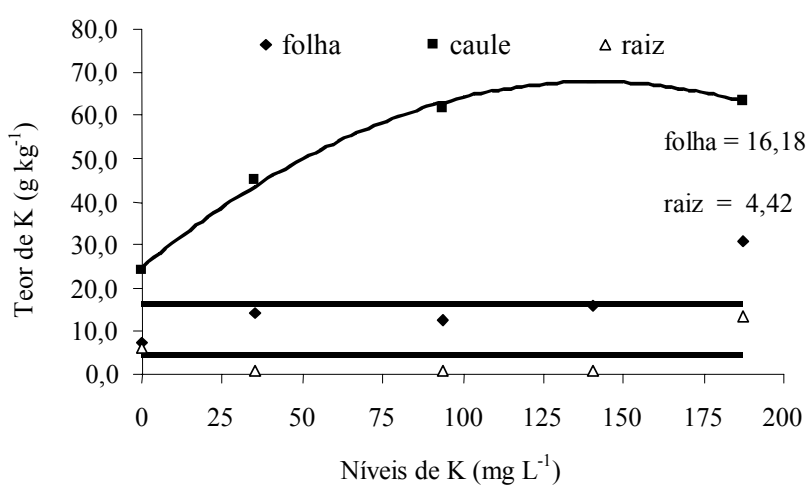

Figura 12 - Teor de potássio em diferentes partes da planta de Heteranthera reniformis em função dos níveis de potássio aos 35 dias após transplante. deste nutriente nas folhas, em comparação ao aumento do teor nos caules e, em menor proporção, nas raízes.

Quanto aos teores de K (Figura 12), observaram-se, nos caules, respostas mais evidentes em função do incremento dos níveis do nutriente, em comparação com folhas e raízes. Isso pode estar relacionado com a maior alocação de biomassa e recursos ocorrida nos caules, onde houve maior demanda, o que provavelmente influenciou a absorção de potássio.

Heteranthera reniformis pode ser considerada uma espécie agressiva quanto ao recrutamento de elementos do meio, por desviar recursos para a alocação de biomassa radicular mesmo em ambientes pobres em fósforo, bem como de biomassa de caules, que se constitui em um órgão alternativo na absorção de radiação solar.

\section{LITERATURA CITADA}

AMOROS, C.; BORNETE, G.; HENRY, C. P. A vegetation based method ecological diagnosis of riverine wetlands. Environ. Manag., v. 25, n. 2, p. 211-227, 2000.

BAATTRUP-PEDERSEN, A.; LARSEN, S. E.; RISS, T. Composition and richness of macrophyte communities in small Danish streams - influence of environmental factors and weed cutting. Hidrobiologia, v. 495, p. 171-179, 2003.

BARRAT-SEGRETAIN, M. H. Biomass allocation in three macrophyte species in relation to the disturbance level of their habitat. Fresh. Biol., v. 46, p. 935-945, 2001.

ESTEVES, F. A. Fundamentos de limnologia. 2.ed. Rio de Janeiro: Interciência, 1998. 602 p.

FERRERO, A. Prediction of Heteranthera reniformis competition with flooded rice using day-degrees. Weed Res., v. 36, p. 197-201,1996.

GARRARD, A. S. L. A.; HALLER, W. T. Nitrogen source, biomass production, and phosphorus uptake in waterhyacinth. J. Aquat. Plant Manag., v. 19, p. 40-43, 1981.

KHEDR, A. H. A.; EL-DEMERDASH, M. A. Distribution of aquatic plants in relation to environmental factors in the Nile Delta. Aquat. Bot., v. 56, p. 75-86, 1997.

KISSMANN, K. G.; GROTH, D. Plantas infestantes e nocivas. 2.ed. São Paulo: Basf Brasileira, 1997. 825 p. T. 1.

Planta Daninha, Viçosa-MG, v. 23, n. 1, p. 33-42, 2005 
MARSCHNER, H. Mineral nutrition of higher plants. San Diego: Academic Press, 1990. 674 p.

MALAVOLTA, E. et al. Avaliação do estado nutricional de plantas: princípios e aplicações. 2.ed. Piracicaba: Potafós, 1989. 319 p.

PETTICREW, E. L.; DROPPO, I. G.; KRONVANG, B. Interactions between sediments and water. Hidrobiologia, v. 494, p. 1-4, 2003.

PETRUCCIO, M. M.; ESTEVES, F. A. Uptake rates of nitrogen and phosphorus in the water by Eichhornia crassipes and Salvinia auriculata. R. Bras. Biol., v. 60, n. 2, p. 229-236, 2000.

REDDY, K. R.; TUCKER, W. F. Productivity and nutrient uptake of water hyacinth, Eichhornia crassipes: I-Effect of nitrogen source. Econ. Bot., v. 37, p. 237-247, 1983.

REJMANKOVA, E. Ecology of creeping macrophytes whith special reference to Ludwigia peploides (H.B.K.) Raven. Aquat. Bot., v. 43, n. 3, p. 283-299, 1992.
RICKELEFS, R. E. A economia da natureza. Rio de Janeiro: Guanabara Koogan, 1996. p. 469.

SALISBURY, F. B.; ROSS, C. W. Plant physiology. 4.ed. Califórnia: Wadsworth Publishing Company, 1992. p. 682.

SARRUGE, J. R. Soluções nutritivas. Summa

Phytopatol., v. 1, n. 3, p. 231-233, 1975.

VASCONCELOS, T.; TAVARES, M.; GASPAR, N. Aquatic plants in the rice fields of the Tagus Valley, Portugal. Hidrobiologia, v. 415, p. 59-65, 1999.

VESCOVI, F. D. et al. Effects of time and duration of competition between rice (Oriza sativa L.) and Heteranthera reniformis Ruiz \& Pavon. In: INTERNATIONAL SYMPOSIUM ON CROP PROTECTION, 61., 1996, Bélgica. Anais... Bélgica: GENT, 1996. p. $1123-1128$.

WETZEL, R. G. Limnologia. 2.ed. Lisboa: Fundação Calouste Gulbenkian, 1993. 915 p. 